\title{
GENDER VARIATION IN OCTOGENARIANS AND NONAGENARIAN PATIENTS UNDERGOING PCI
}

\author{
E .Anil Kumar , K. Nagendra Prasad, A. Siva Prasad
}

\begin{abstract}
:
Background: The aging of the population worldwide will result in increasing numbers of elderly patients, among whom heart disease is the leading cause of death. Changes in cardiovascular physiology with normal aging and prevalence of comorbidities are different between both sex. This results in differences in the effects of common cardiac problems as well as the response to their treatments. Clinical trials in octogenarians and nonagenarians PCI results are limited. The present study aims to analyze the gender variations in respect to the success of PCI in this elderly population.

Methods: This is a retrospective observational study of patients aged $\geq 80$ yrs. with cardiovascular disease undergoing PCI. The prevalence of variables like age distribution, type of presentation, and pattern of angiographic profile, requirement of pre-dilation before stenting and success of PCI has been compared between male and female population. Student " $t$ " test is used for comparison.

Results: The study population consists of 174 patients with female to male ratio of 1:3.7. The mean age is $82.4 \pm 2.9 \mathrm{yrs}$ in males and $82.2 \pm 2.9$ yrs. in females. The minimum age is 80 and maximum is 99 yrs. $74(54 \%)$ male patients and 20 (54.1\%)) female patients presented with chronic stable angina. Incidence of single vessel disease among male population is 97 (70.8\%) and female population is 23 (62.1\%) ( $p$ value=0.3). Rest of them are multi vessel disease. Predilatation is required in $89 \%$ male patients and $86 \%$ female patients $(95 \% C I=0.09$ to $0.14, P$-Value $=0.7) . L A D, L C X$ and RCA angioplasties are comparable between the both groups. Three LMCA PCI in females and 3 SVG PCI in males were done. Successful PCI done in 132 (96.4\%) male patients and 35 (94.6\%) female patients ( $p=0.7$; CI-0.09 to 0.06).

Conclusion: Clinical and demographic features including success of PCI are similar in both female and males in octogenarians and nonagenarians who are undergoing PCI for CAD.
\end{abstract}

Article received on 01 JAN 2017, published on 31JAN 2017.

Anil Kumar. E1 , K. Nagendra Prasad ${ }^{1}$, A. Siva Prasad ${ }^{2}$

${ }^{1}$ Senior Resident, Department of Cardiology ,NIMS, India

${ }^{2}$ Asst.Professor ,Department of Cardiology ,NIMS, India

Corresponding author: Anil Kumar.E

Email: anilenikapalli@gmail.com
Keywords: Octogenarians, Nonagenarians, Percutaneous Coronary Intervention.

\section{INTRODUCTION:}

Aging of the population worldwide will result in increasing number of elderly patients among whom Cardiovascular disease is both the most frequent diagnosis and the leading cause of death among both men and women older than 65 years [1,2,3]. The profile of the common cardiovascular diseases differs in older patients from that in younger patients. Coronary artery disease (CAD) is more likely to involve multiple vessels and to affect the left main artery and occurs with similar frequency in women and in men older than 65 years. Equal numbers of older men and women present with acute myocardial infarction (MI) until the age of 80 years, after which this presentation is more common in women $[6,7]$.

The high morbidity and mortality from cardiovascular disease in the elderly population warrant aggressive approaches to prevention and treatment that are effective in older patients. Another challenge to the physician is that the elderly have more comorbidities such as diabetes, peripheral vascular disease or stroke. Another key factor is that the elderly tend to have more multivessel disease than the population under the age of 65 .

In current practice, up to $25 \%$ of all PCIs are performed in patients over the age of 75 and $12 \%$ are performed in those aged over 80 years, and this number has increased steeply over the past decade $[4,5]$ Although clinical trials have generally excluded elderly patients, a number of observational studies have investigated outcomes after PCI in elderly patients.

Additionally, as the age of patients with CAD increases, the incidence of $\mathrm{CHF}$, prior revascularization, previous $\mathrm{MI}$ and renal insufficiency 
increases substantially. In-hospital complications associated with coronary intervention also increases. The incidence of myocardial infarction, unplanned CABG, and in-hospital death is greater in elderly patients. The traditional risk factors for CAD (hypertension, diabetes mellitus, total cholesterol/HDL ratio) are less prevalent in those over 80 [11]. Clinical trials including elderly patients are limited and recommendations from trials involving younger population lack evidence based support in elderly.

\section{METHODS:}

Study Design: This is a retrospective observation study in a population with cardiovascular disease undergone PCI for CAD between 2010 to 2015 with age more than 80 years. In this study we have analyzed demographic, clinical, angiographic, procedural characteristics of the elderly individuals undergoing PCI.

Elderly people of age more than 80 years undergoing PCI regardless of the history and the cause were being included in the study. The prevalence of variables like type of CAD, age distribution, Predilatation done or not and single vessel disease or multi vessel disease has been compared between male and female population.

\section{RESULTS}

Demographic Characters: A total of 174 population above 80 years undergoing PCI was studied retrospectively. Out of those ,Male patients in the population were $137(78 \%)$, female patients were $37(22 \%)$. The mean age of patients in male population was $82.35 \pm 2.88$ years, and in female population was $82.19 \pm 2.85$ years.(minimum 80 years - maximum 99 years ) (Table 1, Fig.1).

\section{Coronary artery disease:}

Among the cardiac causes for PCI chronic stable angina was the leading cause in a total of 94 members, among male population seen in $74(54 \%)$, among female population in $20(54.1 \%)(95 \%$ CI for difference:(-0.181364, 0.180575)( P-Value $=0.997)$. Incidence of single vessel disease among total population was seen in $120(\mathrm{n}=174)$, among male population was 97 (70.8\%),among female population was 23 (62.1) (95\% CI for difference: $(0.08-0.26)(\mathrm{p}$ value $=0.330$ ). Rest of them had multi vessel disease.

Table 1: Demographic Characters

\begin{tabular}{llll}
\hline & $\begin{array}{l}\text { Total } \\
\text { Populatio }\end{array}$ & Males & Females \\
\hline $\begin{array}{l}\text { Number of Patients } \\
(\%)\end{array}$ & $\mathbf{1 7 4}$ & $137(78)$ & $37(22)$ \\
$\begin{array}{l}\text { Mean Age (Yrs) } \\
\text { Chronic Stable }\end{array}$ & $94(54)$ & $74(54)$ & $20(54.1)$ \\
Single Vessel & $120(68)$ & $97(70.8)$ & $23(62.1)$ \\
Multi Vessel & $54(32)$ & $40(29.2)$ & $14(37.9)$ \\
Predilatation With & $154(88)$ & $122(89)$ & $32(86)$ \\
PCI & & & \\
PCI to & & & \\
LAD & $81(46.5)$ & $62(31.2)$ & $19(51.3)$ \\
LCX & $35(20.1)$ & $28(16.7)$ & $7(18.9)$ \\
RCA & $52(29.8)$ & $44(26.3)$ & $8(21.6)$ \\
LMCA & 3 & - & 3 \\
Success Of PCI & $167(95.9)$ & $132(96.3$ & $35(94.5)$ \\
\hline \hline
\end{tabular}

Fig 1: Percentage incidence of CAD

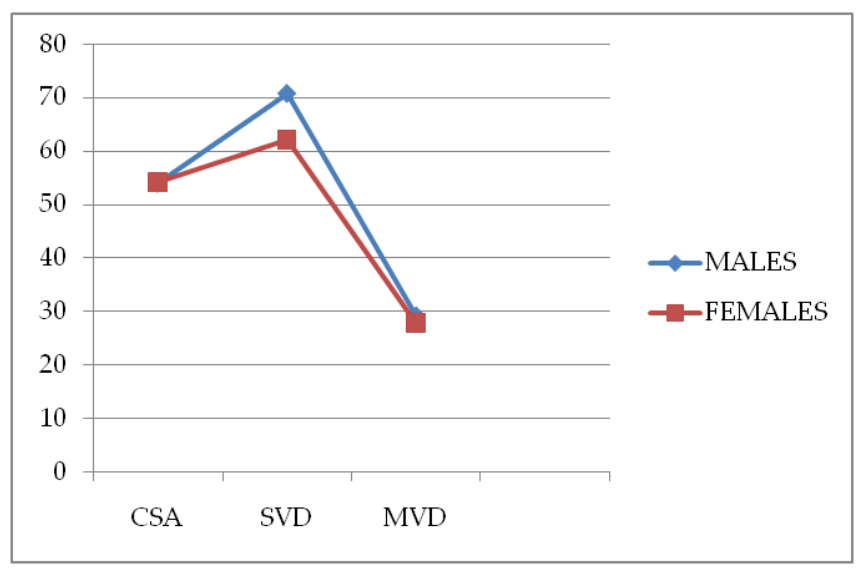

\section{Procedure analysis:}

Predilatation with PCI was done in total of 154 members (88\%), 122 among male population (89\%), in 32 among female population (86\%) $95 \%$ CI for difference: $(-0.096,0.14)(\mathrm{p}$-Value $=0.680)$ indicating complexity of lesions in the elderly people. PCI to LAD was done in a total of 81 members $(46.5 \%), 62$ 
patients among male population (31.2\%), 19 among female population (51.3\%).95\% CI for difference: ($0.31,0.03),(\mathrm{p}$ Value $=0.115)$

PCI to LCX was done in a total of 35 members (20.1\%),28 among male population (16.7\%), in 7 patients among female population (18.9\%) 95\% CI for difference: $(-0.15,0.11)(\mathrm{p}$-Value $=0.760) . \mathrm{PCI}$ to RCA was done in a total of 52 members $(29.8 \%), 44$ among male population(26.3\%),8 among female population $(21.6 \%)(95 \%$ CI for difference: $(-0.10$, $0.19)(\mathrm{p}$-Value $=0.533) \cdot \mathrm{PCI}$ to LMCA was done in total 3 patients all the 3 belong to female population $(95 \%$ CI for difference: $(-0.16,0.006)(\mathrm{p}-$ Value $=0.071)$ (Fig.2).

\section{Fig.2: Percentage of Population with PCI}

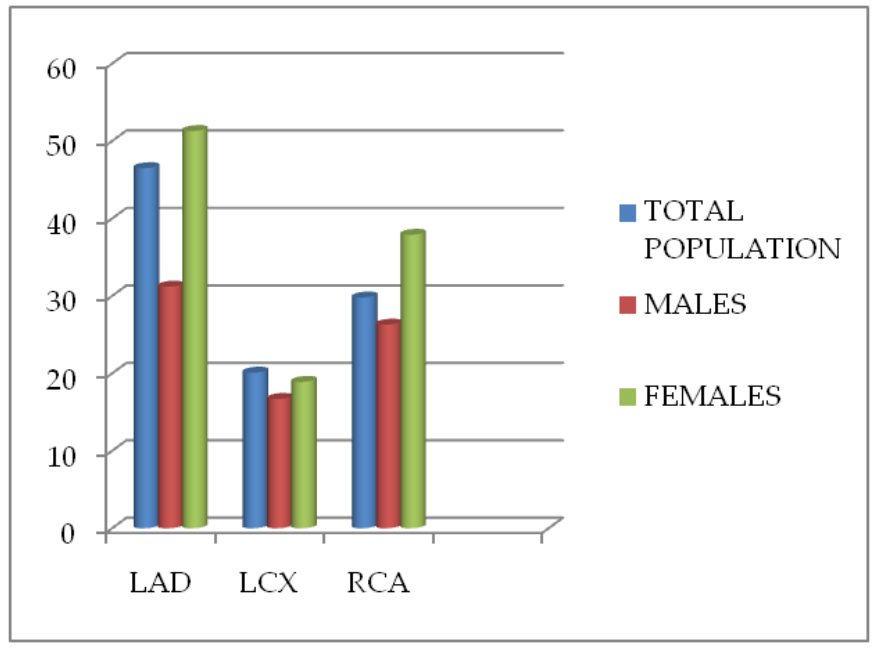

Success of PCI was seen in a total of 167 members (95.9\%), 132 among male population (96.3\%),35 among female population $(94.5 \%)$ 95\% CI for difference: $(-0.09,0.06),(\mathrm{P}-\mathrm{Value}=0.664)$.

\section{DISCUSSION :}

This single centre retrospective study was conducted with a cohort of 174 patients who underwent PCI. In the last decade, it had been proven by a series of studies, that performing PCI on elderly patients $\geq 75$ years may not yield as much risk as had been previously imagined, in spite of the fact that nearly all of these studies focused exclusively on patients with acute myocardial infarction.
In the present study, patients undergoing PCI were predominantly male, and female patients made up about $22 \%$ of the patients in this institution. The mean age of women in this study was consistently older than men with a maximum of 99 years. This result is in line with previous studies indicating that women were less prone to developing cardiac problems than men, with a lag of approximately 10 years between the sexes [13].Studies on elderly patients undergoing PCI have shown less aggressive treatment and higher mortality than in younger patients.

Incidence of single vessel disease was seen more commonly in both the male and female population when compared to multi vessel disease, with chronic stable angina was the most common cause for the patients undergoing PCI in this study population. Pre dilatation was done in majority of population which was equal in both male and female population.(p value of 0.115). Dragana Radovanovic etal supported that no major difference in the management of men and women with unstable angina. Although performed less often than in men, women benefited similarly from PCI.

In this study, PCI to LAD was done in 81 members $(46.5 \%)$,more percentage is seen among female patients with $95 \%$ CI for difference: $(-0.31,0.03),(\mathrm{P}-$ Value $=0.115)$, which remains insignificant difference among the two groups.PCI to LCX was done in a total of 35 members $(20.1 \%)$, with no significant difference among the two groups,95\% CI for difference: $(-0.15,0.11)($ P-Value $=0.760) . P C I$ to RCA was done in a total of 52 members (29.8\%), 44 among male population (26.3\%), 8 among female population $(21.6 \%)$ ( $95 \%$ CI for difference: (-0.10, 0.19) $($ P-Value $=0.533)$. PCI to LMCA was done in total 3 patients all the 3 belong to female population (95\% CI for difference: $(-0.16,0.006)(\mathrm{P}-$ Value $=$ 0.071). In this study there was no significant difference had been observed among the two groups in all the procedure related aspects. Success of PCI was seen in a total of 167 members (95.9\%), 132 among male population (96.3\%),35 among female population (94.5\%) $95 \%$ CI for difference: (-0.09, 
$0.06),(\mathrm{P}-\mathrm{Value}=0.664)$.this signifies that there was no significant differences in the outcomes between male and female population. NEWYORK registry study has shown that in octogenarian population outcomes of PCI has been good when compared to other population $[14,15]$.

\section{CONCLUSIONS :}

Incidence of PCI has been increased among octogenarian population with a high success rates among these population. Overall, our study showed similar outcomes for men and women [8,9] after adjusting for clinical characteristics and ECG findings.

\section{LIMITATIONS:}

First, this was a retrospective study, which may have inherent shortcomings. Relative small sample size may be the main limitation in our study, involving population in a single centre.

\section{REFERENCES:}

First, this was a retrospective study, which may have inherent shortcomings . Relative small sample size may be the main limitation in our study, involving population in a single centre.

1. Alexander KP, Roe MT, Chen AY et al.; for the CRUSADE Investigators. Evolution in cardiovascular care for elderly patients with non-ST segment elevation acute coronary syndromes: results from the CRUSADE National Quality Improvement Initiative. J Am Coll Cardiol 2005;46:1479.

2. Mehta RH, Rathore SS, Radford MJ et al. Acute myocardial infarction in the elderly: differences by age. J Am Coll Cardiol 2001;38:736-41.

3. Kung HC, Hoyert DL, Xu J, et al. Division of vital statistics. Deaths : final data for 2005 . National vital statistics reports. Natl Vital Stat Rep 2008; 56: 1-120.

4. Singh M, Peterson ED, Roe MT et al. Trends in the association between age and in-hospital mortality after percutaneous coronary intervention: National
Cardiovascular Data Registry experience. Circ Cardiovasc Interv2009;2:20.

5. Bauer $\mathrm{T}$, Mollmann $\mathrm{H}$, Weidinger $\mathrm{F}$ et al. Predictors of hospital mortality in the elderly undergoing percutaneous coronary intervention for acute coronary syndromes and stable angina. Int J Cardiol2011;151:164-9.

6. Mehilli J, Ndrepepa G, Kastrati A, et al. Gender and myocardial salvage after reperfusion treatment in acute myocardial infarction. J Am Coll Cardiol2005;45:828-31.

7. Mehilli J, Kastrati A, Dirschinger J, et al. Sex-based analysis of outcome inpatients with acute myocardial infarction treated predominantly with percutaneous coronary intervention. JAMA 2002;287:210-5

8. Mueller C, Neumann FJ, Roskamm H, et al. Women do have an improved long term outcome after non-ST-elevation acute coronary syndromes treated very early and predominantly with percutaneous coronary intervention: a prospective study in 1,450 consecutive patients. J Am Coll Cardiol 2002;40:245-50.

9. Ben-Ami T, Gilutz H, Porath A, et al. No gender difference in the clinical management and outcome of unstable angina. Isr Med Assoc J 2005;7:228-32.

10. Vlaar PJ, Lennon RJ, Rihal CS, et al. Drug-eluting stents in octogenarians: early and intermediate outcome. Am Heart J 2008; 155: 680-686.

11. Forman DE, Chen AY, Wiviott SD, et al. Comparison of outcomes in patients aged $<75,75$ to 84 , and $\geq 85$ years with ST-elevation myocardial infarction (from the ACTION Registry-GWTG). Am J Cardiol 2010; 106: 1382-1388

12. Bauer $\mathrm{T}$, Mollmann $\mathrm{H}$, Weidinger $\mathrm{F}$, et al. Predictors of hospital mortality in the elderly undergoing percutaneous coronary intervention for acute coronary syndromes and stable angina. Int J Cardiol 2011; 151: 164-169. 
13. Shrestha $\mathrm{R}, \mathrm{Xu} \mathrm{J}$, Xie $\mathrm{D}$, et al. Comparison of clinical outcomes of Chinese men and women after coronary stenting for coronary artery disease: a multicentre retrospective analysis of 4,334 patients. J Biomed Res 2014; 28: 368-75.

14. Ciszewski A, Karcz M, Kepka C, et al. Primary angioplasty in patients $>$ or $=75$ years old with STelevation myocardial infarction- one-year follow-up results. Kardiol Pol 2008; 66:828-836.
15. Wenaweser $\mathrm{P}$, Ramser $\mathrm{M}$, Windecker $\mathrm{S}$, et al. Outcome of elderly patients undergoing primary percutaneous coronary intervention for acute STelevation myocardial infarction. Catheter Cardiovasc Interv 2007; 70: 485-490. 